Galloway, A. T., Addessi, E., Fragaszy, D. M., Visalberghi, E. (2005). Social facilitation of eating familiar food in tufted capuchin monkeys (Cebus apella): Does it involve behavioral coordination? International Journal of Primatology, 26(1): 181-189. (Feb 2005) Published by Springer (ISSN: 1573-8604). DOI: 10.1007/s10764-005-0729-7

\title{
Social Facilitation of Eating Familiar Food in Tufted Capuchins (Cebus apella): Does it Involve Behavioral Coordination?
}

Amy T. Galloway, Elsa Addessi, Dorothy M. Fragaszy, and Elisabetta Visalberghi

\begin{abstract}
Social facilitation of eating familiar foods might serve to synchronize eating activities within groups. We aimed to assess whether capuchins (Cebus apella) are prompted to eat when observing other conspecifics eating a familiar food. Subjects were 8 male captive-born tufted capuchins. One pair of capuchins acted as demonstrators for the other 6 observer subjects. In the Experimental condition, the demonstrator pair was given fresh chow in addition to having access to the leftover food and ate continuously. In the Control condition, the demonstrator pair had access to food leftover from the morning feed and ate very little. The initiation of feeding by the demonstrator pair prompted the initiation of feeding behavior in the observers, and the latter ate significantly more of their leftovers in the Experimental than in the Control condition. The tempo of the social facilitation of eating familiar foods in capuchins support isomorphic coordination, a process that occurs when one individual's activity focuses the attention of another individual to the same activity, thereby increasing behavioral similarity in a group.
\end{abstract}




\section{INTRODUCTION}

Most research concerning social influences on feeding behavior has focused on the widely expressed view that social animals gain knowledge about where to eat, what to eat, and how to eat from conspecifics (Galef and Giraldeau, 2001). Since using social information to learn about unknown food is thought to help enlarge the diet in omnivorous species (Kummer, 1971; Nishida, 1987), most of these studies have focused on the effect of social influences on the acceptance of novel foods.

In fact, research indicates that when capuchin monkeys receive novel food while observing group members eating, they eat more of their own novel food (Visalberghi and Fragaszy, 1995). This rise is due to social facilitation, i.e., an increase in the frequency of a behavior already in an animal's repertoire when in the presence of others engaged in the same behavior (Clayton, 1978). This effect occurs regardless of what food group members are eating (Visalberghi and Addessi, 2000), and the intake of novel foods increases by $63.9 \%$ compared to when capuchins are alone (Addessi and Visalberghi, 2001). Moreover, the frequency of the observers' eating behavior increases as the number of group members eating increases (Visalberghi and Addessi, 2000). However, when capuchins are presented with novel foods of two different colors, one of which matches the food eaten by their group members, and the other does not, capuchins' choice is not affected by group members' behavior (Visalberghi and Addessi, 2001; Visalberghi and Addessi, 2003). Therefore, the social influences on the acceptance of novel food do not promote the acquisition of a safe diet, but increases the initial acceptance of novel foods (Visalberghi and Addessi, 2000).

Social facilitation of eating familiar food is worthy to study as well, because (1) it is an important factor affecting eating behavior in humans, and (2) it would promote the synchronization of eating activities within groups of animals. In humans, de Castro (1991) found a positive correlation between meal size and the number of people present. Moreover, when adult subjects ate with other people food intake was $60 \%$ higher than when they ate alone, and they consumed also more water, sodium, and alcohol (Redd and de Castro, 1992). When the effect of group size and acquaintance was investigated by serving dinner to 120 young women alone, in pairs, or in groups of four, Clenenden et al. (1994) found that subjects alone ate less than those in pairs and in groups of four. Moreover, the relationship of dining companions was an important factor contributing to social facilitation: subjects eating with friends ate more dessert than subjects eating with strangers.

Social facilitation of eating familiar foods has been demonstrated in a variety of animals (chickens, Keeling and Hurnik, 1993; dogs, Ross and Ross, 1949; pigs, Hsia and Wood-Gush, 1984; red-winged black birds, Mason and Reidinger, 1981). Social facilitation may be one of the mechanisms underlying behavioral coordination, defined by Coussi-Korbel and Fragaszy (1995) as the process that occurs when one individual's activity focuses the attention of another to the same activity, already in the species' 
behavioral repertoire, thereby increasing behavioral similarity between individuals. Behavioral coordination is thought to support group cohesion because group members will be more efficient foragers (for squirrel monkeys, Boinski, 1987; for birds Crook, 1961; Ward and Zahavi, 1973; Krebs, 1974; Emlen and Demong, 1975; Clayton, 1978, as cited by Coussi-Korbel and Fragaszy, 1995; for a discussion see also Snowdon and Boe, 2003). Similarly, enhanced foraging efficiency has been proposed as a possible hypothesis for the evolution of shoaling in fishes (Pitcher and Parrish, 1993). For example, in guppies (Poecilia reticulata), there is wide experimental evidence that both domesticated strains and wild animals can learn foraging locations and foraging routes by approaching and following conspecifics (Laland and Williams, 1997; Lachlan et al., 1998; Day et al., 2001; Brown and Laland, 2002; Reader et al., 2003).

The evidence for the social facilitation of eating familiar foods in nonhuman primates is still unclear. In one laboratory study, six rhesus macaques (Macaca mulatta) initiated consumption more frequently and ate more food when they were in the presence of a feeding conspecific compared to when they were alone (Harlow and Yudin, 1933). However, the design of this experiment did not include a feeding situation in which focal monkeys ate in the presence of a conspecific that did not have food. Therefore, that the macaques did not eat as much food while alone might be attributed to the effect of isolation rather than social facilitation in the paired condition.

The aim of our experiment was to assess whether the eating behavior of one pair of capuchins prompted six observers to eat more of their familiar food. As shown by the studies on novel food acceptance described above, capuchin monkeys are a good animal model in which to investigate how social influences affect feeding behavior. In fact, they have a very flexible diet (Kinzey, 1997) and, compared to other primate species, a high level of intra-group tolerance (Izawa, 1980; Janson, 1996; Perry and Rose, 1994).

\section{METHODS}

\section{Subjects}

Subjects were eight male captive-born tufted capuchin monkeys (Cebus apella) housed at the University of Georgia. Their ages ranged from three to ten years, and they were all pair-housed. Two pairs had lived together for over three years; the other two pairs had lived together for 6 months. They were fed twice a day, standard Purina $\square$ chow in the morning and a combination of chow and fruit in the afternoon. Subjects were tested in their homecage $(1.37 \times .71 \times 1.80 \mathrm{~m})$ with their cagemate. All eight subjects were housed in a common room $(7.02 \times 3.51 \times 2.44 \mathrm{~m})$. The four cages were arranged so that all subjects could see one another. 


\section{Procedure}

In each trial, one pair of capuchins acted as demonstrators and the other three pairs as observers. The role of each pair of monkeys on a given trial was changed so that all four pairs of capuchins served four times as an observer pair and four times as a demonstrator pair, depending on the trial. On every trial all pairs had continuous access to chow. The chow was given during the morning feeding and remained in the enclosure at the time of data collection, which took place after the morning feeding. If no chow was leftover from the morning feeding (because it had been eaten), then testing was postponed until another day. By ensuring that chow was available before introducing the fresh chow, we were more certain that the subjects were satiated. Therefore, if the subjects ate, we were more confident that it was not because they were hungry. A two-week pilot study conducted to test the procedure above indicated that the capuchins began eating when the experimenters entered the room. The effect lasted approximately 20 min before the monkeys reduced their eating to minimal consumption. This information led to the decision to run several "pre-trials", in which we would follow the same procedure as the regular test trials for 25 min before regular testing began.

Because of the information learned during pilot testing, pre-trials were conducted to allow subjects to return to a baseline state prior to the start of the experimental and control trials. The pre-trial period began as soon as the experimenters entered the testing room (approximately $45 \mathrm{~min}$ after the morning feeding that occurred between 9:00 and 9:30 am), and lasted 25 min. Testing began after the pre-trial period and lasted 3 min. There were two conditions: (1) Experimental (Fresh Chow), in which the demonstrator pair was given fresh chow, and (2) Control (Leftover Chow), in which the demonstrator pair was not given any additional chow. There were 16 experimental trials and 16 control trials; each pair of capuchins acted as the demonstrator pair for 4 experimental and 4 control trials. Experimental and control trials were carried out on different days.

Two experimenters collected data for this study (A. G. and J. N.). During the Experimental condition, one experimenter stood in front of the demonstrator pair's cage, and gave them fresh chow, whereas during the Control condition, the experimenter stood in front of the demonstrator pair's cage without giving them any fresh food. The other experimenter scored the behavior of the remaining six subjects (of the three observer pairs) with scan sampling. During each of the six 30-sec scan periods (comprising the three-min testing trial), this experimenter scored whether each of the six observers ate food. The order in which subjects were scored during each scan was predetermined and counterbalanced across trials. A stopwatch signaled a tone at $30 \mathrm{sec}$ intervals. Inter-rater reliability scores exceeded $90 \%$. 


\section{Behaviors Scored}

The dependent measure was eating behavior by each subject. Eating was defined as "putting food in mouth and chewing it" or "chewing food already in mouth." Pilot data showed that the demonstrators reliably consumed the fresh chow when it was given to them for the entire three-min testing trial, so we did not collect data from the demonstrators.

\section{Analyses}

In order to control for independence between subjects belonging to the same pair, for each subject and for each trial we calculated the frequency of eating behavior in the scans in which their pair-mate was eating and in the scans in which their pair-mate was not eating. These frequencies were compared by Wilcoxon signed ranks test. We carried out this analysis for both the Experimental and Control conditions. Since the eating behavior of the subjects belonging to the same pair was independent (see below), a Wilcoxon signed ranks test was used to analyze differences in the total frequency of eating behavior between the data obtained during the Experimental and Control conditions.

\section{RESULTS}

Individuals in the same pair did not influence each other's eating behavior. In fact, in the Control condition individuals ate their chow significantly more when their pair-mate was not eating than when their pair-mate was also eating ( $T=36, N=8 ; p<0.01$, see Fig. 1$)$, whereas in the Experimental condition this difference was not significant $(T=25, N=8$; NS, see

Fig. 1). Therefore, subjects in a same pair can be considered independent.

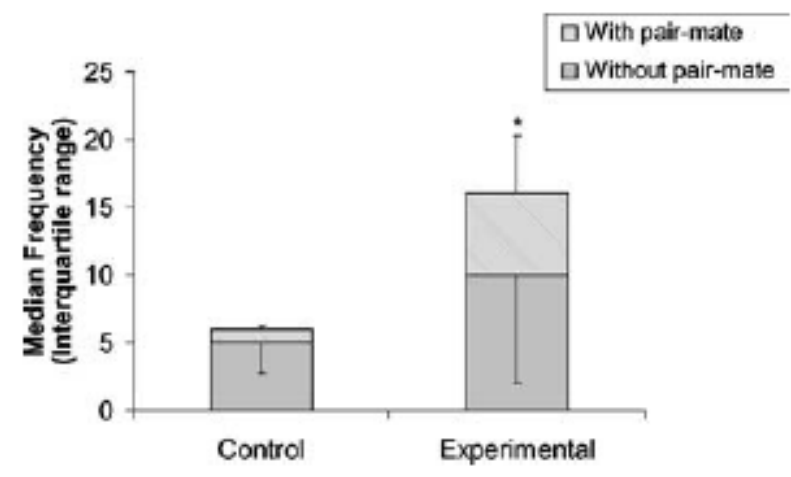

Fig. 1. Frequency of eating behavior in the Experimental and Control conditions, when the pair-mate was eating (striped bars) and when the pair-mate was not eating (solid bars). 
As shown in Fig. 1 in the Experimental condition (when the demonstrators were eating their chow), the observers ate more of their leftover chow than in the Control condition (when the demonstrators rarely or never ate it) $(T=3, N=8 ; P<.05)$.

\section{DISCUSSION}

We showed that the initiation of feeding by a pair of capuchin monkeys prompted initiation of feeding in conspecifics nearby. This supports previous results obtained in various species, including humans, showing that social influences increase the intake of familiar food (Keeling and Hurnik, 1993; Ross and Ross, 1949; Hsia and Wood-Gush, 1984; Mason and Reidinger, 1981; de Castro, 1991; Redd and de Castro, 1992). Our finding extends Visalberghi and Addessi's results concerning novel foods that social facilitation (sensu Clayton, 1978) affects the acceptance of novel foods (Visalberghi and Addessi, 2000, 2001, 2003). The similarity between our result and those obtained for humans by de Castro (de Castro, 1991; Redd and de Castro, 1992) confirms that capuchin monkeys can be considered a good model for studying social influences on feeding behavior, which are among the most important factors affecting eating behavior in our species.

Social facilitation of feeding behavior in capuchins can be an effective mechanism promoting behavioral coordination, as proposed for other species (fishes, Pitcher and Parrish, 1993; squirrel monkeys, Boinski, 1987; birds Crook, 1961; Ward and Zahavi, 1973; Krebs, 1974; Emlen and Demong, 1975; Clayton, 1978). Behavioral coordination has been defined by Coussi-Korbel and Fragaszy (1995) as the process that occurs when one individual's activity focuses the attention of another individual to the same activity, already in the species' behavioral repertoire, thereby increasing behavioral similarity between individuals. In particular, our findings support a specific kind of behavioral coordination, the isomorphic coordination (Coussi-Korbel and Fragaszy, 1995). Isomorphic coordination has three features: it involves actions in the behavioral repertoire (as feeding behavior), it is sequential rather than simultaneous, and it provides information about timing or location.

Finally, it is worthwhile mentioning that social facilitation of eating behavior may be supported by the activity of mirror neurons, i.e., motor neurons that discharge both when a monkey performs a particular action and when it observes another individual (monkey or human) performing a similar action (Rizzolatti et al., 1996, 1999; Ferrari et al., 2003). We believe that the neurophysiological basis of social influences on eating behavior deserves investigation, and the phenomenon of mirror neurons provides a plausible neural mechanism to investigate in this regard. 


\section{ACKNOWLEDGMENTS}

We especially thank Flavia Chiarotti for help with statistical analyses and John Newhouse for help during the data collection. E. Addessi was supported by a fellowship provided by the Consiglio Nazionale delle Ricerche.

\section{REFERENCES}

Addessi, E., and Visalberghi, E. (2001). Social facilitation of eating novel foods in tufted capuchin monkeys (Cebus apella): Input provided, responses affected and cognitive implications. Anim. Cogn. 4: 297-303.

Boinski, S. (1987). Birth synchrony in squirrel monkeys (Saimiri oerstedii): A strategy to reduce neonatal predation. Behav. Ecol. 21: 393-400.

Brown, C., and Laland, K. N. (2002). Social learning of a novel avoidance task in the guppy: Conformity and social release. Anim. Behav. 64: 41-47.

Clayton, D. A. (1978). Socially facilitated behavior. Q. Rev. Biol. 53: 373-392.

Clenenden, V. I., Herman, P. C., and Polivy, J. (1994). Social facilitation of eating among friends and strangers. Appetite 23: 1-13.

Coussi-Korbel, S., and Fragaszy, D. (1995). On the relation between social dynamics and social learning. Anim. Behav. 50: 1441-1453.

Crook, J. H. (1961). The basis of flock organization in birds. In Thorpe, W. H., and Zangwill, O. L. (eds.), Current Problems in Animal Behaviour, Cambridge University Press, Cambridge, pp. 125-149.

Day, R. L., MacDonald, T., Brown, C., Laland, K. N., and Reader, S. M. (2001). Interactions between shoal size and conformity in guppy social foraging. Anim. Behav. 62: 917925.

de Castro, J. M. (1991). Social facilitation of the spontaneous meal size of humans occurs on both weekdays and weekends. Physiol. Behav. 49: 1289-1291.

Emlen, S. T., and Demong, N. J. (1975). Adaptive significance of synchronized breeding in a colonial bird: A new hypothesis. Science 188: 1029-1031.

Ferrari, P. F., Gallese, V., Rizzolatti, G., and Fogassi, L. (2003). Mirror neurons responding to the observation of ingestive and communicative mouth actions in the monkey ventral premotor cortex. Eur. J. Neurol. 17: 1703-1714.

Galef, B. G. Jr., and Giraldeau, L. A. (2001). Social influences on foraging in vertebrates: Causal mechanisms and adaptive functions. Anim. Behav. 61: 3-15

Harlow, H. F., and Yudin, H. C. (1933). Social behavior of primates. J. Comp. Psychol. 16: 171-185. 
Hsia, L. C., and Wood-Gush, D. G. M. (1984). Social facilitation in the feeding behavior of pigs and the effect of rank. Appl. Anim. Ethol. 11: 265-270.

Izawa, K. (1980). Social behavior of the wild black-capped capuchin (Cebus apella). Primates 21: 443-467.

Janson, C. H. (1996). Toward an experimental socioecology of primates: Examples from Argentine brown capuchin monkeys (Cebus apella nigrivittatus). In Norconk, M., Garber, P., and Rosenberger, A. (eds.), Adaptive Radiations of Neotropical Primates, Plenum Press, New York.

Keeling, L. J., and Hurnik, J. F. (1993). Chickens show socially facilitated feeding behavior in response to a video image of a conspecific. Appl. Anim. Behav. Sci. 36: 223-231.

Kinzey, W. G. (1997). New World Primates: Ecology, Evolution and Behavior. Aldine, Hawthorne, NY.

Krebs, J. R. (1974). Colonial nesting and social feeding as strategies for exploiting food resources in the great blue heron (Ardea herodias). Behaviour 51: 99-130.

Kummer, H. (1971). Primate Societies, Harlan Davidson, Arlington Heights, IL.

Lachlan, R. F., Crooks, L., and Laland, K. N. (1998).Who follows whom? Shoaling preferences and social learning of foraging information in guppies. Anim. Behav. 56: 181-190.

Laland, K. N., and Williams, K. (1997). Shoaling generates social learning of foraging information in guppies. Anim. Behav. 53: 1161-1169.

Mason, R. J., and Reidinger, R. F. (1981). Effects of social facilitation and observational learning on feeding behavior of the red-winged blackbird (Agelaius phoeniceus). Auk. 98: 778784.

Nishida, T. (1987). Local traditions and cultural transmission. In Smuts, B., Cheney, D., Seyfarth, R., Wrangham, R., and Struhsaker, T. (eds.), Primate Societies, University of Chicago Press, Chicago, pp. 462-474.

Perry, S., and Rose, L. (1994). Begging and transfer for coati meat by white-faced capuchin monkeys, Cebus capucinus. Primates 35: 409-415.

Pitcher, T. J., and Parrish, J. K. (1993). Functions of shoaling behaviour in telosts. In Pitcher, T. J. (ed.), The Behavior of Teleost Fishes, 2nd edn. Chapman \& Hall, London, pp. 363-440.

Reader, S. M., Kendal, J. R., and Laland, K. N. (2003). Social learning of foraging sites and escape routes in wild Trinidadian guppies. Anim. Behav. 66: 729-739.

Redd, M., and de Castro, J. M. (1992). Social facilitation of eating: Effects of social instruction on food intake. Physiol. Behav. 52: 749-754.

Rizzolatti, G., Fadiga, L., Fogassi, L., and Gallese, V. (1999). Resonance behaviors and mirror neurons. Archives italiennes de biologie 137: 85-100. 
Rizzolatti, G., Fadiga, L., Gallese, V., and Fogassi, L. (1996). Premotor cortex and the recognition of motor actions. Cognitive Brain Res. 3: 131-141.

Ross, S., and Ross G. W. (1949). Social facilitation of feeding behavior in dogs: II. Feeding after satiation. J. Genet. Psychol. 74: 293-304.

Snowdon, C. T., and Boe, C. Y. (2003). Social communication about unpalatable foods in tamarins. J. Comp. Psychol. 117: 142-148.

Visalberghi, E., and Addessi, E. (2000). Seeing group members eating a familiar food enhances the acceptance of novel foods in capuchin monkeys. Anim. Behav. 60: 69-76.

Visalberghi, E., and Addessi, E. (2001). Acceptance of novel foods in Cebus apella: Do specific social facilitation and visual stimulus enhancement play a role? Anim. Behav. 62: 567576.

Visalberghi, E., and Addessi, E. (2003). Food for thoughts: Social learning and the feeding behavior in capuchin monkeys. Insights from the laboratory. In Fragaszy, D., and Perry, S. (eds.), Traditions in Non-human Animals: Models and Evidence. Cambridge University Press, Cambridge.

Visalberghi, E., and Fragaszy, D. (1995). The behaviour of capuchin monkeys, Cebus apella, with novel foods: The role of social context. Anim. Behav. 49: 1089-1095.

Ward, P., and Zahavi, A. (1973). The importance of certain assemblages of birds as "information centers" for food-finding. Ibis 115: 517-534. 